\title{
Magnesium sulphate as an alternative and safe treatment for severe persistent pulmonary hypertension of the newborn
}

\author{
J-F Tolsa, J Cotting, N Sekarski, M Payot, J-L Micheli, A Calame
}

\begin{abstract}
Eleven newborns admitted consecutively to the neonatal unit with respiratory failure and severe persistent pulmonary hypertension (PPHN) were included in a clinical trial to assess the efficacy of magnesium sulphate $\left(\mathrm{MgSO}_{4}\right)$ in the treatment of PPHN. A loading dose of $200 \mathrm{mg} / \mathrm{kg} \mathrm{MgSO}_{4}$ was given over 20 minutes, followed by a continuous infusion of $20-150 \mathrm{mg} / \mathrm{kg} / \mathrm{hour}$ to obtain a magnesium blood concentration between 3.5 and $5.5 \mathrm{mmol} /$. Mean (SD) duration of treatment was $75 \cdot 5(\mathbf{1 9 \cdot 8 )}$ hours. No other vasodilatory drug was administered before or during the treatment and patients were not hyperventilated. Mean (SEM) $\mathrm{PaO}_{2}$ values significantly increased from $42.6(8.8)$ before treatment to $70.3(24 \cdot 1) \mathrm{mm} \mathrm{Hg}$ after 24 hours, with no change in pH or Pco2. Oxygen index and alveolar-arterial oxygen gradient $\left(\mathrm{A}-\mathrm{aDO}_{2}\right)$ were significantly lower after 24 hours; respectively, $46 \cdot 8(15 \cdot 2)$ to $28 \cdot 0$ (9.0) and 624.3 (11.3) to $590(58) \mathrm{mm} \mathrm{Hg}$. Mean airway pressure could be significantly reduced from $19.5(3 \cdot 1)$ to 13.9 (3.9) $\mathrm{cm} \mathrm{H}_{2} \mathrm{O}$ after 72 hours. Mean ventilatory time support was 131 hours and mean total oxygen dependency 10 days. No systemic hypotension nor any other adverse effect were noted. All infants survived and the neurodevelopmental assessment was normal at 6 and 12 months of age.

It is concluded that magnesium sulphate is a non-aggressive and low-cost treatment of short duration which is easy to apply. It may have a role in the various treatment of PPHN.
\end{abstract}

(Arch Dis Child 1995; 72: F184-F187)

Keywords: persistent pulmonary hypertension, magnesium sulphate, newborn.

Neonatology Unit, Paediatric

Department,

University Hospital,

CHUV-1011-Lausanne,

Switzerland

J-F Tolsa

J Cotting

N Sekarski

M Payot

J-L Micheli

A Calame

Correspondence to:

Dr J-F Tolsa.

Accepted 7 February 1995 approaches, including various vasodilatory agents $^{34}$ and extra-corporeal membrane oxygen (ECMO) ${ }^{5}{ }^{6}$ have been advocated, with variable success. More recently inhaled nitric oxide (NO) treatment has been given to term and preterm neonates with encouraging results $^{7-9}$ and its use and potentially toxic effects studied. ${ }^{10}$

At high serum concentrations, magnesium is a muscle relaxant, a sedative, and a potent vasodilatory agent. ${ }^{11}$ It has been used for a long time in hypertension induced by pregnancy ${ }^{12}$ with variable success but no adverse effect on the fetus and the newborn. ${ }^{13}$ Animal studies have shown that magnesium can prevent and reduce hypoxia induced pulmonary hypertension $^{14-16}$ and two clinical reports have shown its benefit in the rescue treatment of PPHN in neonates. ${ }^{1718}$ Recently we described in a preliminary report its possible use as a first line treatment without alkalinisation or administration of other vasodilatory drugs. ${ }^{19}$ In order to assess the efficacy of magnesium as sole treatment, we set up a prospective clinical trial in which all infants with PPHN confirmed by echocardiography would be given $\mathrm{MgSO}_{4}$ as first line treatment.

\section{Methods}

Eleven newborns admitted consecutively to the neonatal unit with respiratory failure and profound hypoxaemia due to severe persistent pulmonary hypertension were enrolled into the trial. The diagnosis of PPHN was considered when there was either a persistent hypoxaemia $(\mathrm{PaO} 2$ of $<50 \mathrm{~mm} \mathrm{Hg}$ or $6.67 \mathrm{kPa}$ ) out of proportion to the degree of severity on the chest radiograph despite an adequate ventilatory support and/or an important lability of oxygenation with great variations in $\mathrm{PaO} 2$ without changes in ventilator settings. Before inclusion all the infants either had an oxygen index above 40 (mean (SEM) $46.8(15 \cdot 2)$ ) or an $\mathrm{A}-\mathrm{aDo}_{2}$ of $\geqslant 610 \mathrm{~mm} \mathrm{Hg}$ (mean (SEM) 624.3 (11.3)); heart defects were excluded and pulmonary hypertension always confirmed by echocardiography. ${ }^{20}$ The clinical findings in these infants are shown in the table.

Four infants were inborn and seven outborn. There were four females and seven males. Gestational age ranged from 35 to 40 weeks (mean (SD) $36.7(1.3)$ weeks) and birthweight from 2260 to $3570 \mathrm{~g}$ (mean (SD) 2956 (449) g). All were appropriate for gestational age and none of them presented with congenital malformations. Mean Apgar scores 
Clinical findings in the patients studied

\begin{tabular}{|c|c|c|c|c|c|}
\hline $\begin{array}{l}\text { Case } \\
\text { No }\end{array}$ & $\begin{array}{l}\text { Birthplace } \\
\text { (in/outborn) }\end{array}$ & Sex & $\begin{array}{l}\text { Gestation } \\
\text { (weeks) }\end{array}$ & $\begin{array}{l}\text { Birthweight } \\
\text { (g) }\end{array}$ & Primary diagnosis \\
\hline 1 & Outborn & $\mathrm{F}$ & 38 & 3160 & AS, thrombocytopenia \\
\hline 2 & Inborn & $\mathbf{M}$ & 37 & 2970 & \\
\hline 3 & Outborn & $\mathbf{M}$ & 37 & 2500 & SBS, pneumonia \\
\hline 4 & Inborn & $\mathbf{F}$ & 36 & 2630 & AS \\
\hline 5 & Inborn & $\mathrm{F}$ & 36 & 2600 & AS, neonatal hypocalcaemia \\
\hline 6 & Outborn & $\mathbf{M}$ & 37 & 3570 & HMD \\
\hline 7 & Inborn & $\mathbf{M}$ & 36 & 2900 & AS \\
\hline 8 & Outborn & $\mathrm{F}$ & 35 & 2260 & HMD \\
\hline 9 & Outborn & $\mathbf{M}$ & 36 & 2870 & AS \\
\hline 10 & Outborn & $M$ & 36 & 3500 & $\begin{array}{l}\text { Pneumonia, pneumothorax, } \\
\text { thrombocytopenia }\end{array}$ \\
\hline 11 & Outborn & $\mathbf{M}$ & 40 & 3560 & AS, perinatal asphyxia \\
\hline
\end{tabular}

AS: aspiration syndrome; HMD: hyaline membrane disease; SBS: Streptococcus B sepsis.

were $8 \cdot 1$ at one minute and $8 \cdot 2$ at five minutes. Only one term infant had perinatal asphyxia (Apgar 8/3/5). Seven infants presented with aspiration syndrome, two with hyaline membrane disease, one with pneumonia and one with Streptococcus B sepsis. Informed consent was obtained from all parents.

All patients were first given routine supportive treatment including: (1) haemodynamic support by volume expansion up to 20 to $30 \mathrm{ml} / \mathrm{kg}$ and, if necessary, with continuous dobutamine infusion at 5 to $20 \mathrm{mg} / \mathrm{kg} /$ minute; (2) sedation with morphine infusion at 10 to $20 \mathrm{mg} / \mathrm{kg} /$ hour with additional doses of $0 \cdot 1 \mathrm{mg} / \mathrm{kg}$ if necessary and; (3) appropriate ventilatory support (Bear Cub infant ventilator). Before and during $\mathrm{MgSO}_{4}$ treatment, heart rate, mean arterial blood pressure (MABP), temperature, and ventilator settings with inspired oxygen fraction $\left(\mathrm{FIO}_{2}\right)$, respiratory rate, peak inspiratory pressure (PIP), positive end expiratory pressure (PEEP), and mean airway pressure (Paw) were recorded at two hour intervals during the first day of treatment and then four to six times a day. The blood gas measurements $\left(\mathrm{pH}, \mathrm{PaO}_{2}, \mathrm{PCO} 2\right)$ were obtained through an indwelling arterial umbilical catheter (Argyle 3.5 or 5.5 French guage) positioned at $\mathrm{L} 3$ to $\mathrm{L} 4$, and measured with an ABL 300 acid base laboratory analyser.

All the variables and results are expressed as mean \pm one standard deviation (SD). Before $\mathrm{MgSO}_{4}$ infusion was begun, all infants were ventilated with $100 \% \mathrm{FIO}_{2}$ at a rate of $45 \cdot 1$ $(15 \cdot 7) /$ minute with high PIP of 35.9 (4.4) $\mathrm{cm} \mathrm{H}_{2} \mathrm{O}$ and a PEEP of $3.5(0.9) \mathrm{cm}$ $\mathrm{H}_{2} \mathrm{O}$. Mean airway pressure was $19.5(3 \cdot 1) \mathrm{cm}$

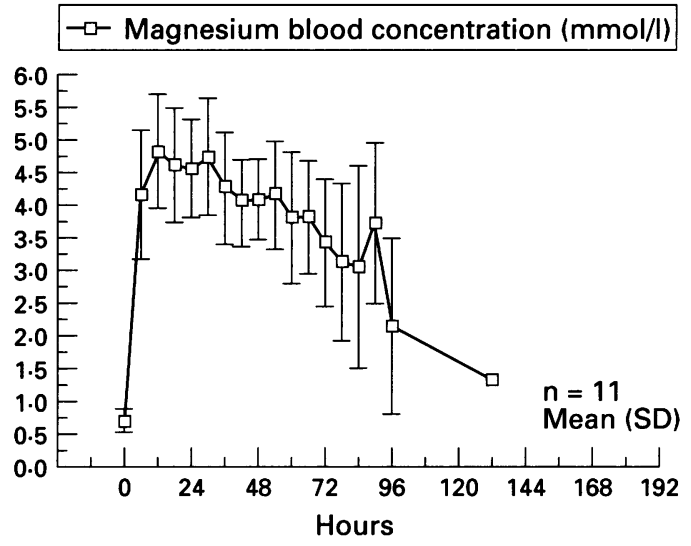

Figure 1 Blood magnesium concentration ( $\mathrm{mmol} / \mathrm{l}$ ) in relation to treatment (in hours).
$\mathrm{H}_{2} \mathrm{O}$. Blood gas analysis showed a $\mathrm{pH}$ value of $7 \cdot 34(0 \cdot 09)$ and a $\mathrm{PCO} 2$ of $45 \cdot 1(12 \cdot 0) \mathrm{mm} \mathrm{Hg}$. Hypoxaemia was confirmed with a $\mathrm{PaO} 2$ of $42.6(8 \cdot 8) \mathrm{mm} \mathrm{Hg}$. In case 6 arterial $\mathrm{PO}_{2}$ could not be obtained before the start of treatment because of a technical difficulty. Severity of impairment of gas exchange was evaluated after oxygen index and $\mathrm{A}-\mathrm{aDO}_{2}$ had been calculated according to the formulas: oxygen index $=\mathrm{Paw} \times \mathrm{FIO}_{2} / \mathrm{PaO}_{2}$ and $\mathrm{A}-\mathrm{aDO}_{2}$ $(\mathrm{mm} \mathrm{Hg})=760 \times \mathrm{FIO}_{2}-\left(\mathrm{PaO}_{2}+\mathrm{PCO} 2+47\right)$, where $\mathrm{PaO}_{2}(\mathrm{~mm} \mathrm{Hg})$ is the post-ductal arterial oxygen tension and $\mathrm{PCO} 2(\mathrm{~mm} \mathrm{Hg})$ the carbon dioxide tension. $\mathrm{MgSO}_{4}$ infusion was started at a postnatal age of $25.0(12 \cdot 2)$ hours (range 8-53 hours). Pancuronium was administered if the PIP was above $30 \mathrm{~cm} \mathrm{H}_{2} \mathrm{O}$ and or if the patient's respiration was not synchronous with the ventilatory rate.

A loading dose of $200 \mathrm{mg} / \mathrm{kg} \mathrm{MgSO}_{4}$ diluted to $10 \%$ in sterile water was given intravenously over 20 minutes, followed by a continuous infusion of 20 to $150 \mathrm{mg} / \mathrm{kg} /$ hour, to obtain a magnesium blood concentration between 3.5 and $5.5 \mathrm{mmol} / 1$. Magnesium blood concentrations were monitored twice hourly within the first 24 hours and three to four times a day after stabilisation. No other vasodilatory drug was used before or during the treatment. The patients were not hyperventilated or alkalinised.

Once the $\mathrm{PaO}_{2}$ was stabilised, ventilator settings were then reduced first by decreasing the pressures and then the $\mathrm{FiO}_{2}$. Pancuronium was usually stopped during the second day of treatment and patients ventilated in the prone position as soon as possible.

Multiple means were compared by analysis of variance followed by a $t$ test using the Bonferroni correction if ANOVA showed significant treatment effects. ${ }^{21}$ Paired $t$ tests were used to compare values before $\mathrm{MgSO}_{4}$ infusion and after 24, 48, and 72 hours of treatment. A p value of $<0.05$ was considered significant.

\section{Results}

The blood magnesium concentration in relation to treatment (in hours) is illustrated in fig 1. Magnesium blood concentrations increased rapidly during the first three hours of treatment to reach a mean (SD) value of $4 \cdot 16$ $(0.99) \mathrm{mmol} / \mathrm{l}$ after six hours of treatment. With continuous infusion, the blood concentration was then kept between 3.5 and $5.5 \mathrm{mmol} / \mathrm{l}$. Mean duration of treatment was $75(19 \cdot 8)$ hours with a range from 44 to 114 . No important hypocalcaemia was noted and only a few infants received transiently a $10 \%$ calcium gluconate infusion.

The evolution of the $\mathrm{PaO}_{2}$ is shown in fig 2 . In all infants $\mathrm{PaO}_{2}$ improved rapidly and increased from $42.6(8.8) \mathrm{mm} \mathrm{Hg}$ before treatment to $70.9(15.5)$ six hours later, and to 70.3 $(24 \cdot 1)$ after 24 hours of treatment $(p<0 \cdot 01)$. At 48 and 72 hours of treatment, $\mathrm{PaO}_{2}$ values remained significantly higher - respectively, $71.7(15.2) \mathrm{mm} \mathrm{Hg}(\mathrm{p}<0.001)$ and 81.5 $(14 \cdot 3)(\mathrm{p}=0 \cdot 001)$, at lower $\mathrm{FIO}_{2}$. 


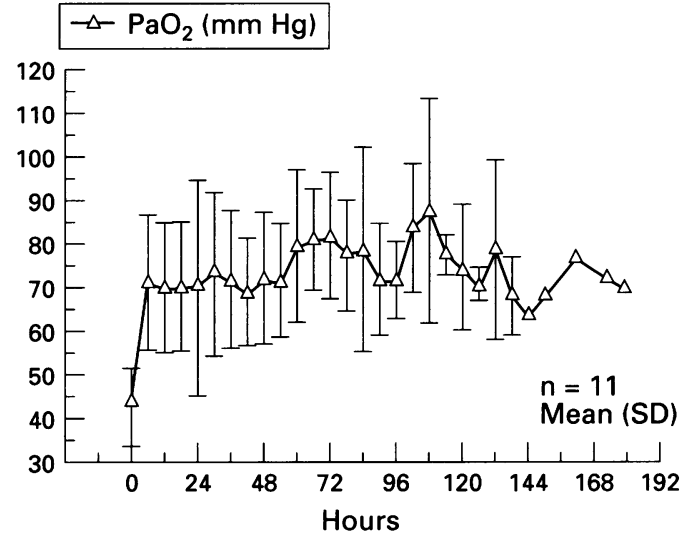

Figure $2 \mathrm{PaO}_{2}(\mathrm{~mm} \mathrm{Hg})$ in relation to treatment (in hours).

No significant changes in $\mathrm{pH}, \mathrm{PcO} 2$, and MABP were noted after 24,48 , and 72 hours of treatment ( $\mathrm{pH} 7.38(0.07), 7.38(0.05)$, and 7.41 (0.06); PCO2 42.7 (6.3), 43.1 (6.4), and 42.9 (7) $\mathrm{mm} \mathrm{Hg}$; MABP 47.9 (3.8), 50.5 $(3 \cdot 1)$, and $59 \cdot 0(5 \cdot 8) \mathrm{mm} \mathrm{Hg})$.

Paw significantly decreased from 19.5 (3.1) $\mathrm{cm} \mathrm{H}_{2} \mathrm{O}$ before treatment to 13.9 (3.9) after 72 hours $(\mathrm{p}<0.01)$ (fig 3$)$. Ventilatory support was needed for a mean of 5.5 days to a maximum of eight days. Oxygen dependency varied from six to 15 days, with a mean of 10 days. None of the infants developed chronic lung disease.

At the start of the $\mathrm{MgSO}_{4}$ treatment, the oxygen index was above 40 in six of 11 infants and the $\mathrm{A}-\mathrm{aDO}_{2}$ greater than $620 \mathrm{~mm} \mathrm{Hg}$ in seven. Oxygen index significantly decreased from $46.8(15.2)$ before treatment to 28.0 $(8 \cdot 7)$ after 24 hours $(\mathrm{p}<0.05)$, and remained below 25 after 40 hours of treatment. $\mathrm{A}-\mathrm{aDo}_{2}$ significantly decreased from $624.3(11 \cdot 3)$ to $590.0(57.8) \mathrm{mm} \mathrm{Hg}(\mathrm{p}<0.05)$ within the first 24 hours of treatment. A sharp decrease was subsequently observed over the next 48 hours.

During $\mathrm{MgSO}_{4}$ treatment, an expected decrease in the heart rate was noted $(164.5$ $(15.8)$ before treatment to $134.4 \quad(8.6)$ beats/minute after 24 hours), requiring an adjustment of the dobutamine infusion between 5 and $20 \mathrm{mg} / \mathrm{kg} /$ minute. No adverse effect during and after treatment was observed, including no clinically relevant fall in blood pressure.

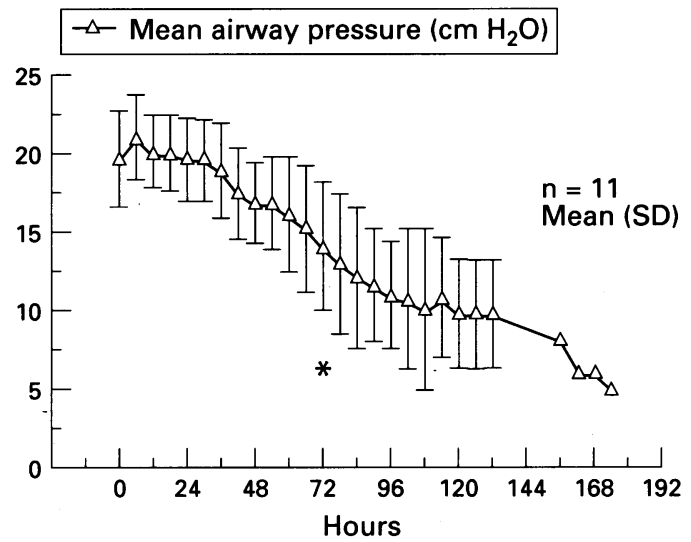

Figure 3 Mean airway pressure $\left(\mathrm{cm} \mathrm{H}_{2} \mathrm{O}\right)$ in relation to treatment (in hours). ${ }^{\star} p$ Value between 0 and 72 hours of treatment was significantly lower.
All infants survived, had a normal neurological examination, and normal head ultrasound scans at hospital discharge.

Ten of the 11 infants were examined in the developmental unit between 6 and 12 months of age and all had a normal development. One child lives abroad and is normal according to his parents and paediatrician.

\section{Discussion}

The regulation of the pulmonary circulation before and after birth reflects a balance between factors producing active pulmonary vasoconstriction and vasodilation. ${ }^{22}$ Despite a better understanding of the underlying pathophysiology and the various treatments that have been proposed, ${ }^{23}$ pulmonary hypertension remains a potentially fatal complication among newborns. ${ }^{24}$ In the absence of specific pulmonary vasodilators, ECMO and other vasodilating agents given by inhalation have been used or are currently under investigation. 2526

At high serum concentrations, magnesium is a muscle relaxant, a sedative, and a potent vasodilatory drug. Its effects on the vascular system have been studied in animals. ${ }^{15} 16$ It is a modulator of vascular contraction and an activator of many cellular processes, including cation transport and modulation of membrane excitability, and it is a physiological calcium antagonist. ${ }^{11}$

$\mathrm{MgSO}_{4}$ has already been given as rescue treatment to newborns with severe PPHN. ${ }^{18}$ In this study we used magnesium without any other vasodilatory agent or hyperalkalinisation. Our 11 patients all presented with a severe PPHN, evidenced by refractory hypoxaemia with a high oxygen index and $\mathrm{A}-\mathrm{aDO}_{2}$. After a loading dose of $\mathrm{MgSO}_{4}$, the magnesium blood concentration of $3.5-5.5 \mathrm{mmol} / 1$ was rapidly obtained and easily maintained with a continuous infusion. During treatment, a rapid increase in $\mathrm{PaO}_{2}$ was observed, allowing a progressive reduction in Paw and $\mathrm{FIO}_{2}$, resulting in a decrease of severity indices. Furthermore, with these high magnesium blood concentrations, babies were more stable and had fewer $\mathrm{PaO}_{2}$ fluctuations. This was probably due to the sedative and relaxing effects of magnesium. Nursing in the prone position was then possible, shortening the duration of ventilation and oxygen dependency that are usually required by these very sick neonates.

None of the known side effects of high dose magnesium was observed. The slight decrease in heart rate was easily corrected by dobutamine support. Blood pressure remained stable and increased progressively with postnatal age. Feeding was well tolerated.

Despite high indices of mortality, all infants survived. At discharge from hospital they all had normal neurological findings and normal brain ultrasonography. None of them developed chronic lung disease and at follow up all had normal development. Sensory hearing loss has been reported in infants with PPHN. ${ }^{27}$ This has not yet been detected in our patients. 
In conclusion, this report provides evidence that magnesium can play part in the treatment of persistent pulmonary hypertension of the newborn. It is a non-aggressive treatment of short-duration and low cost. Based on these encouraging results, all patients presenting to our unit with PPHN are currently receiving $\mathrm{MgSO}_{4}$ as the first drug of choice in a prospective protocol. Clinical controlled studies in life threatening conditions, however, are difficult to perform. Nevertheless, comparison between different approaches in the treatment of PPHN is certainly necessary for the evaluation of their respective benefits.

Experimental studies of magnesium and its possible interactions with natural vasodilators, such as prostacyclins, nitric oxide, and the guanylate cyclase pathway, would be suitable areas to investigate in the future.

1 Krummel TM, Lazar J, Greenfield BV, Kirkpatrick DG Mueller KW, Kerkering MO, et al. Alveolar-arterial oxygen gradients versus the neonatal pulmonary insufficiency index for prediction of mortality in ECMO candiciency index for prediction of mortality

2 Ortiz RM, Cilley RE, Bartlett RH. Extracorporeal membrane oxygenation in pediatric respiratory failure. Pediatr Clin North Am 1987; 34: 39-46.

3 Goetzmann BW, Sunshine P, Johnson JD, Wennberg RP Hackel A, Merten DF, et al. Neonatal hypoxia and pulmonary vasospasm: response to tolazoline. $\mathcal{f}$ Pediatr 1976; 89: 617-21.

4 Käpää $P$, Koivisto $M$, Ylikorkala $O$, Kouvalainen $K$. Prostacyclin in the treatment of neonatal pulmonary hypertension. F Pediatr 1985; 107: 951-3.

5 Bartlett RH, Roloff DW, Cornel RG, Andrews AF, Dillon PW, Zwischenberger JB. Extracorporeal circulation in neonatal respiratory failure: A prospective randomized neonatal respiratory failure: A prost

6 Stolar CJH, Snedecor SM, Bartlett RH. Extracorporeal membrane oxygenation and neonatal respiratory failure: membrane oxygenation and neonatal respiratory failure: tion. $\mathcal{F}$ Pediatr Surg 1991; 26: 563-71.

7 Roberts JD, Polaner DM, Lang P, Zapol WM. Inhaled nitric oxide in persistent pulmonary hypertension of the newborn. Lancet 1992; 340: 818-9.

8 Kinsella JP, Neish SR, Ivy DD, Shaffer E, Abman SH. Clinical responses to prolonged treatment of persistent pulmonary hypertension of the newborn with low doses of inhaled nitric oxide. $f$ Pediatr 1993; 123: $103-8$
9 Abman SH, Kinsella JP, Schaffer MS, Wilkening RB. Inhaled nitric oxide in the management of a premature newborn with severe respiratory distress and pulmonary newborn with severe respiratory distress

10 Miller OI, Celermajer DS, Deanfield JE, Macrae DJ. Guidelines for the safe administration of inhaled nitric oxide. Arch Dis Child 1994; 70: F47-9.

11 Altura BM, Altura BT. Magnesium ions and contraction of vascular smooth muscles: relationship to some vascular diseases. FASEB $\mathcal{f} 1981$; 40: 2672-9.

12 Wischnik A, Hiltmann WD, Hettenbach A, Schmidt $R$, Zieger $W$, Neises $M$, et al. Influence of high-dose IV $\mathrm{MgSO}_{4}$ therapy in pregnancy on mother and child Clinical and laboratory findings. In: Lasserre B, Durlach J, eds. Magnesium - A relevant ion. London: John Libbey \& Co, 1990: 453-64.

13 Stone SR, Pritchard JA. Effect of maternally administered magnesium sulfate on the neonate. Obstet Gynecol 1970; 35: 574-7.

14 Cropp GJA. Reduction of hypoxic pulmonary vasoconstriction by magnesium chloride. $\mathcal{F}$ Appl Physiol 1968; 24: $755-60$.

15 Mathew R, Altura BT, Altura BM. Strain differences in pulmonary hypertensive response to monocrotaline alkaloid and the beneficial effect of oral magnesium treatment. Magnesium 1989; 8: 110-6.

16 Abu-Osba YK, Rhydderch D, Balasundaram S, Galal O, Rejial A, Halees Z, et al. Reduction of hypoxia-induced pulmonary hypertension (HIPH) by $\mathrm{MgSO} 4$ in sheep. Pediatr Res 1990; 27: $351 \mathrm{~A}$.

17 Abu-Osba YK, Manasra K, Galal O, Rejjal A. Treatment of pulmonary hypertension of newborn (PPHN) with magnesium. Peditra Res 1990; 27: 294A.

18 Abu-Osba YK, Galal O, Manasra K, Rejial A. Treatment of severe persistent pulmonary hypertension of the newborn severe persistent pulmonary hypertension of the newborn
with magnesium sulphate. Arch Dis Child 1992; 67: 31-5.

19 Tolsa J-F, Cotting J, Sekarski N, Calame A. Le sulfate de magnésium: une alternative dans le traitment de l'hypertension pulmonaire persistante de nouveau-né? Schweiz Med Wochenschr 1993; 123: 5A.

20 Yock PG, Popp RL. Noninvasive estimation of right ventricular systolic pressure by Doppler ultrasound in patients with tricuspid regurgitation. Circulation 1984; 70: 657-62.

21 Snedecor GW, Cochran WG. Statistical methods. Ames, Iowa: Iowa State University Press, 1967.

22 Heymann MA. Regulation of the pulmonary circulation in the perinatal period and in children. Intensive Care Med 1989; 15: S9-12.

23 Roberts JD, Shaul PW. Advances in the treatment of persistent pulmonary hypertension of the newborn. Pediatr Clin North Am 1993; 40: 983-1004.

24 Yu VIH. Persistent pulmonary hypertension in the newborn. Early Hum Dev 1993; 33: 163-75.

25 Curtis J, O'Neill T, Pettett G. Endotracheal administration of tolazoline in hypoxia-induced pulmonary hypertension. Pediatrics 1993; 92: 403-8.

26 Bindl L, Fahnenstich H, Peukert U. Aerosolised prostacyclin for pulmonary hypertension in neonates. Arch Dis Child 1994; 71: F214-6.

27 Hendricks-Munoz KD, Walton JP. Hearing loss in infants with persistent fetal circulation. Pediatrics 1988; 81: 650-6. 